Author's Reply

\section{Reply to Comment on: Ong KK, Petry CJ, Emmett PM et al.; ALSPAC study team (2004) Insulin sensitivity and secretion in normal children related to size at birth, postnatal growth, and plasma insulin-like growth factor-I levels. Diabetologia 47:1064-1070}

To the Editor: Despite obvious population differences, the data on insulin sensitivity and insulin secretion reported by Invitti and co-workers in 660 obese Italian children and adolescents aged 6 to 18 years show many consistencies with our own recent study in 851 representative UK children, all aged 8 years [1], and also with earlier studies in children and adults.

With regard to insulin sensitivity, as in many other studies, while Invitti and co-workers found no overall birthweight association, multivariate analyses indicate that it is the combination of lower birthweight and larger childhood (or adult) size that predicts the most insulin-resistant subjects. The available early growth data in our study revealed that, in the majority of insulin-resistant children, there had been a transition from lower birthweight to larger postnatal size which occurred largely in the first 2 to 3 years of life [1], an important hypervariable period for weight gain [2].

In the absence of significant numbers of glucose-intolerant subjects, insulin secretion generally follows the degree of insulin resistance. However, this relationship is subject to a high degree of variance, and we noted that three recognised risk factors for type 2 diabetes in adults (thinner birth size, shorter stature and lower circulating IGF-I levels) were associated with lower levels of insulin secretion for the same degree of insulin resistance [1] (Fig. 1). Whether these factors predict the risk of adolescent type 2 diabetes and glucose intolerance, independently of insulin resistance, remains to be confirmed.

DOI 10.1007/s00125-004-1564-7

Received: 17 September 2004 / Accepted: 23 September 2004

Published online: 17 November 2004

(C) Springer-Verlag 2004

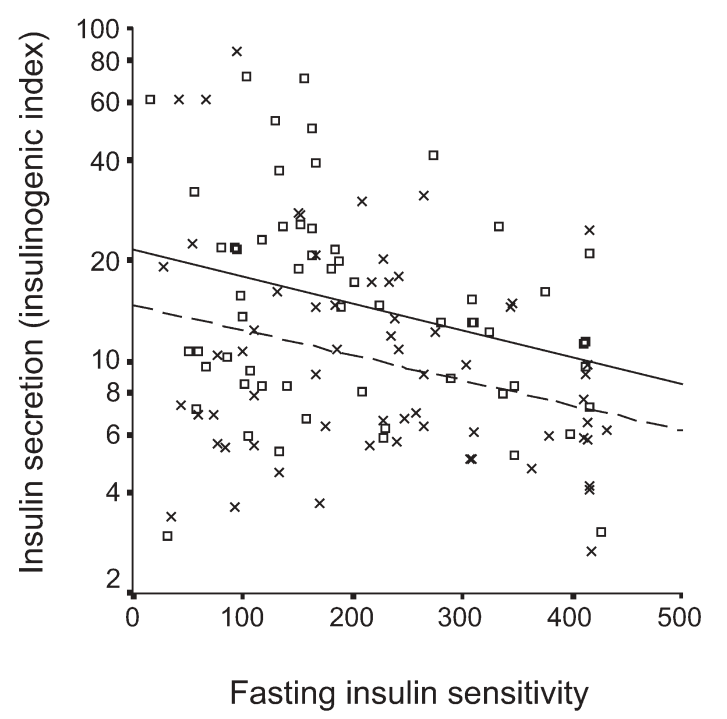

Fig. 1. Variation in insulin secretion $30 \mathrm{~min}$ post-oral glucose according to the degree of fasting insulin sensitivity was related to current childhood height. We observed a $p$ value of 0.008 for tallest (white squares, solid line) vs shortest (black crosses, dotted line) height quartile, adjusted for mid-parental target height. Data are for children aged 8 years old [2]

K. K. Ong, D. B. Dunger, on behalf of the Avon Longitudinal Study of Parents and Children (ALSPAC) study team Department of Paediatrics, University of Cambridge, Addenbrookes Hospital, Cambridge, UK

\section{References}

1. Ong KK, Petry CJ, Emmett PM et al.; ALSPAC study team (2004) Insulin sensitivity and secretion in normal children related to size at birth, postnatal growth, and plasma insulinlike growth factor-I levels. Diabetologia 47:1064-1070

2. Ong KK, Ahmed ML, Emmett PM, Preece MA, Dunger DB; ALSPAC study team (2000) Association between postnatal catch-up growth and obesity in childhood: prospective cohort study. BMJ 320:967-971

D. B. Dunger (

Department of Paediatrics, University of Cambridge,

Addenbrookes Hospital, Box 116, Cambridge, CB2 2QQ, UK

E-mail: dbd25@cam.ac.uk

Tel.: +44-1223-763405, Fax: +44-1223-336996 